\title{
Urban IDPs and Poverty: Analysis of the Effect of Mass Forced Displacement on Urban Poverty in Bosnia and Herzegovina
}

\author{
Nermin Oruc \\ Ulnternational University of Sarajevo, Department of Economics, \\ Bosnia-Herzegovina \\ noruc@ius.edu.ba
}

\author{
CroEconSur \\ Vol. 17 \\ No. 1 \\ June 2015 \\ pp. $47-70$
}

Received: September 2, 2014 Accepted: November 13, 2014

Research Article

doi:10.15179/ces.17.1.2

\section{Abstract}

This paper analyzes the effect of mass forced displacement on urban poverty in Bosnia and Herzegovina. The process of displacement in Bosnia and Herzegovina involved "forced evictions", implying no choice in displacement decision, meaning that this type of rural-urban migration was not a rational decision driven by economic motives. Consequently, this can possibly lead to a larger incidence of poverty among displaced people. The paper starts with a discussion of the specific features of the process of forced displacement and their possibly different effect on urban poverty compared to voluntary migration, based on qualitative evidence collected through interviews with people who experienced forced displacement during the conflict in the 1990s. Then, the probit model of determinants of poverty, based on the Living Standards Measurement Survey data, was estimated in order to provide empirical evidence of the effect of mass 
forced displacement on urban poverty, as well as the difference in the poverty incidence among displaced people compared to voluntary migrants. The results suggest that consumption is significantly lower among displaced households, while incidence of poverty is not affected by displacement status. The evidence also contributes to the migration literature by providing specific results about the relationship between mass forced displacement and urban poverty.

Keywords: migration, conflict, displacement, urban poverty

JEL classification: $\mathrm{I} 32, \mathrm{R} 23$

\section{Introduction ${ }^{1}$}

Events that cause mass forced displacement of people, such as conflicts or natural disasters, are not new (Bell-Fialkoff, 1993), but are gaining in importance due to the increased frequency of occurrence of migrant inflows resulting from such events around the globe. ${ }^{2}$ Consequently, the migration literature has started devoting attention to this type of migration. However, so far the socio-economic effects of migration as a result of large-scale displacement of people have not been largely analyzed in the migration literature. This paper provides empirical evidence about the effect of mass forced displacement (also known in the Western Balkans as "ethnic cleansing") on urban poverty in Bosnia and Herzegovina $(\mathrm{BiH})$, which should contribute to a better understanding of the phenomenon of forced displacement and its consequences.

1 This paper was financially supported by the CERGE-EI GDN CEE Research Competition 2010 Contract RRC X-106. We thank GDN and CERGE-EI for their support. We also thank Ira N. Gang from Rutgers University for his extensive comments to the earlier version of this paper, and to the participants at the 11th GDN conference in Prague in August 2010 for their comments.

2 UNHCR reported around 42.8 million people of concern to the UNHCR in 2005 (UNHCR, 2014). These people are mainly displaced due to conflicts or natural disasters. Natural disasters in particular are requiring attention as it is expected that climate change will be the leading factor influencing migration in the near future. For example, Myers (2005) estimates that about 200 million people will have to be displaced from their current places of living by 2050. (This is the most widely cited estimate. But other authors go even up to 1 billion in their estimates of the number of displaced people as a consequence of climate change by 2050). 
Although $\mathrm{BiH}$ recorded considerable growth in GDP in the post-war period, which had positive impact on the reduction of poverty in the country, about 18 percent of the Bosnian population are still below the poverty line, while another 30 percent are just above it (UNDP, 2007). Much of this poverty has been concentrated in urban areas (World Bank, 2006). A specific feature of ruralurban migration in $\mathrm{BiH}$ during the transition period was that the movement of migrants was not driven by purely economic motives, but by security concerns during a period of severe ethnic conflict. The statistics on poverty indicate that 37 percent of internally displaced persons (IDPs) and refugees are poor and socially excluded, mainly due to the fact that they moved to new surroundings, lost their pre-war social networks and have difficulty entering the labor market due to loss of social capital (Kondylis, 2008). The status of returnees is also very difficult, as the majority of returnees do not have social or health insurance ${ }^{3}$, while they face discrimination by local authorities. Consequently, understanding the effect of mass displacement of people during the conflict on urban poverty can contribute to better design and targeting of poverty reduction programs in a post-conflict society.

Ethnic cleansing during the wars in the Balkans in the 1990s was a war strategy to artificially create a territory with a majority of the population of a warring party's ethnic group by mass forced resettlement of population of all other ethnic groups (Oruc, 2009). Charges by the International Criminal Tribunal for the Former Yugoslavia (ICTY) against the Bosnian Serb ethnic group's political and military leaders include in many cases ethnic cleansing as one of the crimes they committed. Ethnic cleansing in $\mathrm{BiH}$ was particularly extensive, as the majority of municipalities were "cleansed" (meaning that all individuals of other ethnic groups were forced to flee their homes), which caused displacement of about 50 percent of the total population of $\mathrm{BiH}$. Half of the displaced, or about 1.2 million people, then decided to emigrate abroad (Ibreljic et al., 2006), while another million people became IDPs. For this reason, $\mathrm{BiH}$ was chosen as a relevant case

3 The available estimates suggest that 50 percent of IDPs and returnees still pay for health services for their children even in cases where they have health insurance (UNICEF, 2008). 
for the analysis of the effect of mass displacement on urban poverty, which is the main aim of the paper.

Urban areas in Bosnia were particularly affected by the ethnic cleansing, causing movement of people in both directions: from and to the cities. On one side, the largest displacements were observed from the largest cities, and on the other, cities became the main destinations of these refugees. The three largest cities in BiH - Sarajevo, Banja Luka and Mostar - were controlled by the three different ethnic groups and were the main sources and destinations of refugees. The displacements included exchange of inhabitants between these cities, but also acceptance of refugees from other places, including rural areas. This type of migration was not driven by economic opportunities in these cities, but by a search for a "safe haven". Also, it caused significant change in the structure of the population living in these cities, in terms of education level, type of skills, social networks, etc. The change in the structure of population of the largest cities in $\mathrm{BiH}$ in terms of different determinants of poverty is expected to affect the rates and trends in poverty in these cities.

The question which this paper attempts to answer is whether displacement status of households in the urban areas in $\mathrm{BiH}$ is affecting the incidence of poverty among these households. Comparison between different types of displacement, voluntary and forced, should allow for identification of the impact of the different determinants of migration on the poverty in urban areas resulting from such displacement. Moreover, the differences in the direction of migration in terms of whether migrants moved mainly to the capital or other cities, resulting from the motives for such migration, and their subsequent impact on intercity differences in poverty, will be explored.

The paper is structured as follows. First, the process of ethnic cleansing, with its specific features that can affect urban poverty in a different manner than voluntary migration, is explained based on evidence collected through a qualitative research. Then, the methodology for analysis of the effect of 
ethnic cleansing on urban poverty, including details about data used and their descriptive statistics, is presented. In section four, the paper presents the main findings from econometric estimation of the model of determinants of poverty. Finally, section five concludes.

\section{Motivation: Ethnic Cleansing as a Specific Type of Migration}

Before the 1990s, BiH was a federal state within Yugoslavia, a republic with very mixed ethnic structure. According to the 1991 census, the country's population was composed of three main ethnic groups, considered as the "constituent people" of the country: Bosniaks (43 percent), Bosnian Serbs (33 percent) and Bosnian Croats (18 percent). ${ }^{4}$ The conflict in $\mathrm{BiH}^{5}$ began in April 1992 and ended in December 1995, by US-backed negotiations in Dayton, Ohio. This war was characterized by mass resettlement of people, as a result of the main goal of some warring parties to pursue a policy of ethnic cleansing of the territory they controlled and artificially create the opportunity to claim control over that territory. As a consequence of such strategies, about half of the population was resettled during the war, of which approximately 25 percent was displaced internally and the other 25 percent emigrated abroad (MHRR, 2005). The result was an almost total division of population along ethnic lines. As the above figures show, this was a case of large-scale forced displacement of people, where the displaced individuals had no option of remaining, but were forced to leave their homes. The individuals were targeted on the basis of their ethnicity. ${ }^{6}$

4 This sums up to about 94 percent of the total population. Other ethnic groups, considered as minorities, are Roma, Jews and other groups. In total there are 17 different minorities in the country.

5 There are different views among the opposing parties in $\mathrm{BiH}$ about the character of this conflict. For those fighting on the government's side (mainly Bosniaks), it was aggression by Serbia (international conflict) and for separatists (mainly Serbs), it was a civil war. The ICTY, in several of its statements and verdicts, declared it was a civil conflict with international features.

6 This is an important feature of ethnic cleansing, which can allow for generalization of the findings from this paper to other types of forced displacement. For example, in the case of natural disasters or certain development projects, individuals are not targeted randomly, but on the basis of their place of living. 
Mass forced displacement of people caused by events such as conflicts or natural disasters is characterized by a set of distinguishing features compared to other types of migration, which can result in various socio-economic consequences of such displacement. Therefore a separate analysis of this type of migration needs to be conducted to bring necessary insight into this problem, by taking into account important differences between voluntary and forced migration. Various authors (for example, Van Hear, 1998; Turton, 2003), when discussing different definitions of types of forced migration, have not taken into account two other important distinguishing features of forced migration, namely the magnitude of migration ${ }^{7}$ and the influence of "no choice" displacement ${ }^{8}$ on subsequent migration. According to Stark (2004: 325): "Refugee flows differ from standard migration (henceforth migration) in two important respects: the flow of refugees is typically a group movement - a large number of people move simultaneously - as opposed to a sequenced movement of individuals; and refugee flows are overwhelmingly from distinctly poor economies".

With the purpose of better understanding the process of ethnic cleansing characterized by forced evictions, a small-scale investigation of the process of displacement of people during the conflict in $\mathrm{BiH}$ in the 1990s was conducted. This event was chosen as it may be considered as one of the most striking examples of ethnic cleansing, representative also of other types of migrations falling into the broad category of mass displacement. The results of this investigation are expected to reveal to what extent the model of voluntary migration is suitable for the explanation of the process of ethnic cleansing and if not, how it should be extended or amended.

With the purpose of investigating specific features of ethnic cleansing that took place in $\mathrm{BiH}$, twelve semi-structured interviews ${ }^{9}$ were conducted. Due to the

7 "It is clear that refugee flows can deprive countries of a significant proportion of their population. Thus an estimated one in seven Afghans, one in ten Bosnians, one in eleven Eritreans and one in thirteen Burundians lived outside their country as refugees in 2001-2002" (Koser and Van Hear, 2003: 2).

8 Leckie (1994) used the term "forced evictions" to describe displacement of people where they were not given any option to stay, thus their displacement was not the result of a decision-making process based on the evaluation of push and pull factors. This term will be applied in this paper as well.

9 The questionnaire used in these semi-structured interviews is available at request. 
different types of forced migrants from $\mathrm{BiH}$, it was decided to perform twelve interviews, three for each of the alternative types of displaced households: refugees, returned refugees, internally displaced, or returned internally displaced. Three major cities with the highest concentration of displaced people - Sarajevo, Mostar and Banja Luka ${ }^{10}$ - were chosen in the first stage of sampling. In the second stage, potential interviewees were randomly ${ }^{11}$ selected from online phone directories $^{12}$ of three telephone service providers from these cities. Then, each of the interviewees was asked several brief questions, related to their ethnic origin, current displacement status and willingness to take part in the interview. In each group, three households were chosen from a different ethnic group and in the whole group of twelve interviewees, half of them were female, half highly educated and half displaced from non-urban areas. A main objective of the semistructured interviews was to identify differences in the motives and patterns of displacement between the internally displaced and refugees. Moreover, they provided useful information about the differences in migration decision-making between individuals with different levels of education.

Nine respondents explained that they were forced to move and that they went to the closest place which they considered as a "safe haven". ${ }^{13}$ The other three interviewees had been living in a municipality which was under the control of their ethnic group. Thus, these interviewees did not face a direct threat to their lives. They explained that their motive for migration was primarily economic, but can also be considered as affected by the war, which reduced the options available. The choice of the final destination was influenced by the "network effect", since two-thirds of the respondents, both internally displaced 10 Here, Sarajevo was the main displacement destination site for ethnic Bosniaks, Mostar for ethnic Croats and Banja Luka for ethnic Serbs.

11 The purpose of the survey was not to collect a large number of responses, but just initial information about the magnitude of ethnic cleansing conducted by each warring party, in order to have at least some evidence on this, instead of taking a subjective position. Therefore, the representativeness of the sample was not of particular importance. At least a certain degree of unbiasedness was achieved through random selection.

12 In a country without census data and street address directories available, this was the best possible source for selection of respondents. Thus, the possible selection bias of choosing respondents who have a phone can only be acknowledged and accepted in such circumstances.

13 A "safe haven" was any place which was controlled by a group of the same ethnicity as the respondent. In such a place, they were facing indirect threat, but at least not the certainty of being killed. 
and refugees, stated that they had relatives or close friends living at their final destination. The interviewees were also asked several questions about the process of displacement. The questions in this section of the questionnaire were slightly different, as they were adjusted according to individual displacement experience. The majority of cases of displacement took place in a family context. Returned refugees and returned internally displaced persons were also asked questions on their return experience. The results of these interviews did not reveal any clear differences in demographic characteristics between displaced and returned displaced households, which indicates that the decision to displace and decision to return were two different decisions, influenced by different factors. ${ }^{14}$ However, this issue was not explored further as the main motive for investigation was understanding the process of displacement, not return.

The above investigation has shown that, in assessing the process of displacement of individuals from Bosnia and Herzegovina, two types of individuals can be distinguished: those who were forced to displace and those who were not, but did face indirect threats and pressures of a worsened economic situation. In the example of displacement from $\mathrm{BiH}$, two different types of situations in which individuals found themselves at the beginning of the war can be distinguished. The first type, which can be called a type A situation, is one in which individuals were living in a municipality controlled by authorities of the same ethnic group, thus they were not faced with forced eviction. The level of indirect threat to households was different, depending on the proximity of the place to the fighting zones. However, the threat was random, meaning that all individuals in one place, regardless of their ethnicity or other characteristics, were facing the same level of threat. A type B situation is one where individuals were living in an area controlled by a group of a different ethnicity, thus being faced with forced eviction. ${ }^{15}$ These people usually did not have a choice to stay

14 This may be used as an argument for separate analysis of these two processes, displacement and return of migrants.

15 According to the available data on the displacement in $\mathrm{BiH}$, almost 100 percent of individuals who were in a type B situation were forced to leave their homes during the conflict. In addition, there were takeovers of some municipalities by an opposing ethnic group. Since other ethnic groups had already been evicted, this takeover usually implied eviction of the total population of the municipality, just at different points of time. 
and also were generally not allowed to take any valuables with them. ${ }^{16}$ This type of displacement mainly took place in the first few months of the war. It was non-random, but dependent on the combination of household characteristics and control of a municipality by a specific ethnic group. It is accepted that there were some households which were living in a type B situation, but decided not to leave, in spite of the risk such a decision carried. However, these were infrequent cases and it is expected that creating a variable that distinguishes different types of displacement by combining available data on ethnic origin and type of local government in a municipality will capture the vast majority of cases.

\section{Methodology}

\subsection{Data and Descriptive Statistics}

The dataset used for the empirical analysis in this study is the World Bank's Living Standards Measurement Survey (LSMS) conducted in 2001. ${ }^{17}$ The LSMS was originally conducted among 5,400 households in 25 municipalities in $\mathrm{BiH}$ in 2001. The survey collected responses to the questions on migration from all members of a household older than 15 . However, the displacement decision had been made predominantly at the household level, allowing us to take a household as a unit of analysis and use responses provided by the head of the household. The dataset contains key information about income, consumption, demographic characteristics of a household and other information necessary for conducting the analysis of determinants of poverty.

\footnotetext{
16 The type B situation can be compared to a flooded area, or an area affected by a development project. These similarities give an argument for using the evidence from the analysis of ethnic cleansing displacement for explanation of displacement as a result of natural disasters and development projects.

17 There are more recent survey data available in $\mathrm{BiH}$. The Agency for Statistics of $\mathrm{BiH}$ conducted three waves of the "Living in BiH" survey, in 2002, 2003 and 2004, and two Household Budget Surveys, in 2007 and 2011. However, only the data from the 2001 survey contain the information about consumption and migration experience necessary for this analysis, so this one was used. Although the data are not new, the focus of this paper is not to investigate the current level of poverty in $\mathrm{BiH}$, but the relationship between migration and poverty, for which this dataset is appropriate.
} 
The dataset also contains information about forced displacement of people during the war, which allows analysis of the impact of such displacement on poverty in urban areas. From the question about the displacement status of households, it is possible to distinguish six different groups of households based on their current displacement status: 1) "stayers" (no displacement during the war), 2) returned internally displaced households ${ }^{18}$, 3) returned refugee households, 4) internally displaced households, 5) returned refugee-internally displaced households ${ }^{19}$, and 6) refugees. ${ }^{20}$

The remainder of the section presents the results of descriptive analysis of the dataset, relevant for analysis of the research question, as well as for developing the econometric model presented in the next section. First, the standard table of descriptive statistics of variables that will be used in the subsequent regression analysis is presented.

Table 1: Descriptive Statistics of Variables Used in the Regression Model

\begin{tabular}{l|c:c}
\hline Variable & Mean & Std. Dev. \\
\hline Female headed households & 0.28 & 0.45 \\
\hline Age & 39.94 & 21.67 \\
\hline Child (age < 16) & 0.15 & 0.36 \\
\hline Old (age $>60$ ) & 0.24 & 0.42 \\
\hline Primary education & 0.19 & 0.39 \\
\hline Secondary education & 0.35 & 0.48 \\
\hline Tertiary education & 0.06 & 0.24 \\
\hline Household size & 3.70 & 1.56 \\
\hline Employed & 0.21 & 0.41 \\
\hline Self-employed & 0.04 & 0.21 \\
\hline Unemployed & 0.29 & 0.457 \\
\hline Migrant & 0.21 & 0.41 \\
\hline
\end{tabular}

Source: Author's calculations based on LSMS (2001).

18 It is important to understand the difference between terms such as "internally displaced" and "refugee". Internally displaced are those who were displaced within $\mathrm{BiH}$, while refugees migrated abroad during the war. Consequently, returned internally displaced households are those that returned from within $\mathrm{BiH}$, and returned refugees are those that returned from abroad to their pre-war place of living.

19 These households are those that were repatriated from other countries to $\mathrm{BiH}$, and were not allowed to return to their pre-war place of living, but had to choose another place of living within $\mathrm{BiH}$.

20 Refugees from other countries in $\mathrm{BiH}$. 
As Table 1 shows, 21 percent of households in the sample used for the regression analysis migrated during the war. Average values of demographic characteristics of the households are not much different from the average values for the entire urban population, suggesting good degree of representativeness of the sample. For education level, the benchmark category is no education. The large proportion (around 45 percent) of people without education in the sample can be explained by the fact that the sample includes children.

Second, the main characteristics of urban poverty are analyzed in order to understand urban poverty as such, and then the breakdown of poverty by migration status of households is presented. Table 2 presents some basic characteristics of the urban population of $\mathrm{BiH}$.

Table 2: Descriptive Statistics about Urban Population in Bosnia, by Poverty Status

\begin{tabular}{|c|c|c|c|c|c|c|}
\hline & \multicolumn{2}{|c|}{ Poor } & \multicolumn{2}{|c|}{ Non-poor } & \multicolumn{2}{|c|}{$A l l$} \\
\hline & Mean & Std. Dev. & Mean & Std. Dev. & Mean & Std. Dev. \\
\hline Female headed households & 0.19 & 0.39 & 0.19 & 0.39 & 0.19 & 0.39 \\
\hline Age & 34.55 & 22.72 & 40.50 & 21.51 & 39.28 & 21.89 \\
\hline Child (age < 16) & 0.25 & 0.43 & 0.14 & 0.35 & 0.16 & 0.37 \\
\hline Old $($ age $>60)$ & 0.18 & 0.39 & 0.25 & 0.43 & 0.23 & 0.42 \\
\hline Primary education & 0.20 & 0.40 & 0.19 & 0.39 & 0.19 & 0.39 \\
\hline Secondary education & 0.31 & 0.46 & 0.36 & 0.48 & 0.35 & 0.48 \\
\hline Tertiary education & 0.04 & 0.19 & 0.07 & 0.26 & 0.06 & 0.24 \\
\hline Household size & 4.75 & 1.85 & 3.54 & 1.44 & 3.70 & 1.56 \\
\hline Employed & 0.07 & 0.26 & 0.24 & 0.43 & 0.21 & 0.41 \\
\hline Self-employed & 0.02 & 0.15 & 0.05 & 0.22 & 0.04 & 0.21 \\
\hline Unemployed & 0.45 & 0.50 & 0.26 & 0.44 & 0.30 & 0.46 \\
\hline Migrant & 0.67 & 0.47 & 0.36 & 0.48 & 0.42 & 0.49 \\
\hline
\end{tabular}

Source: Author's calculations based on LSMS (2001).

As we can see from Table 2, people living in larger households are more vulnerable to poverty. Moreover, almost half of the urban poor ( 44.6 percent) are unemployed. Being unemployed appears to be one of the most important factors determining poverty status. Another group vulnerable to living in poverty are children below 16 years of age. Being a child is associated with poverty status 
( 25 percent). Also, living in a female headed household is associated with poverty status; 18.8 percent of the poor in urban areas live in female headed households. In Bosnia, 21 percent of respondents living in urban areas are found to be migrants. As for the individuals' migration status, 66 percent of poor people in the urban areas in Bosnia are migrants. This suggests that incidence of poverty among migrants in urban areas is about three times larger than among nonmigrants.

If we distinguish between the capital city and other urban areas (Table 3), we can see that significant differences exist. If we calculate poverty rates for different groups based on their place of residence, we can again see that significant differences exist. Poverty rates in the capital are lower - 9.46 percent in Sarajevo. The percentage is significantly higher in other urban areas (16.4 percent), and is even above the poverty rate in rural areas (13.6 percent).

Table 3: Urban Income and Poverty Measures in BiH in 2001

\begin{tabular}{|c|c|c|}
\hline & Capital & Other urban areas \\
\hline Headcount ratio (FGT, $\alpha=0$ ) & $\begin{array}{r}0.117 \\
(0.007)\end{array}$ & $\begin{array}{r}0.163 \\
(0.006)\end{array}$ \\
\hline Poverty depth (FGT, $\alpha=1)$ & $\begin{array}{r}0.029 \\
(0.002)\end{array}$ & $\begin{array}{r}0.042 \\
(0.002)\end{array}$ \\
\hline Poverty severity (FGT, $\alpha=0$ ) & $\begin{array}{r}0.012 \\
(0.001)\end{array}$ & $\begin{array}{r}0.018 \\
(0.001)\end{array}$ \\
\hline Sen index 100 & 4.116 & 6.004 \\
\hline Sen-Shorrocks-Thon index*100 & $\begin{array}{r}5.599 \\
(0.003)\end{array}$ & $\begin{array}{r}8.003 \\
(0.004) \\
\end{array}$ \\
\hline Watts index & $\begin{array}{r}3.996 \\
(0.002)\end{array}$ & $\begin{array}{r}5.940 \\
(0.002)\end{array}$ \\
\hline Number of observations & 749 & 1266 \\
\hline
\end{tabular}

Notes: Standard errors in parentheses. The poverty measures use an absolute poverty line of KM 1,566, based on the energy threshold of 2,100 calories per day. The headcount ratio, poverty depth and poverty severity are, respectively, the P-alpha measure calculated with alpha equal to zero, one and two (see Foster, Greer and Thorbecke, 1984). Values for FGT indices are calculated using the World Bank's AdePT software, while other indices were calculated using DASP v2.3 for Stata.

Source: Author's calculations based on LSMS (2001).

All the poverty indices presented in Table 3 show that poverty is significantly larger in other urban areas. For instance, the headcount ratio for Sarajevo (capital 
of $\mathrm{BiH}$ ) is 11.7 percent, whereas for other urban areas it is much higher, 16.3 percent. This ratio is even larger than for rural areas. An explanation often used to explain such a large difference is that many smaller urban areas (not the capital city) were developed by attracting workforce for new large enterprises. Most of these enterprises did not survive the period of transition to the market economy, which caused high unemployment in such urban areas that had been relying on those large enterprises. This consequently has led to such large poverty figures. Still, this issue is worth exploring further. An additional explanation could be the direction of displacement during the conflict in $\mathrm{BiH}$, which is explored in this paper.

Table 4 includes some descriptive statistics about migrants and non-migrants in urban areas. Comparing poverty rates for migrants and non-migrants, we can see that the poverty rate among migrants is slightly larger than the poverty rate among non-migrants, suggesting that migrant status could be one of the determinants of urban poverty in Bosnia. The proportion of female headed households in urban areas is larger among non-migrants compared to migrants. The share of children below the age of 16 among non-migrants in urban areas is only 1 percent, and among migrants it is 37 percent. As regards the level of the individuals' human and social capital, we can see that non-migrants are more educated on average, the share of unemployed is larger among migrants in urban areas, while the share of employees is larger among the group of non-migrants. In countries with forced migration, migrants have been displaced from their houses and have lost a large proportion of their physical capital, but even more important is that they have lost social capital, which creates additional obstacles for labor market participation and education. The fact that lack of social capital among migrants in Bosnia has created additional difficulties for them is confirmed by other studies as well (Kondylis, 2008). This lack of social capital creates obstacles for labor market participation of this group of people, and subsequently increases the probability of falling into and remaining in poverty. 
Table 4: Descriptive Statistics about Urban Population in Bosnia, by Migration Status

\begin{tabular}{|c|c|c|c|c|c|c|}
\hline & \multicolumn{2}{|c|}{ Migrants } & \multicolumn{2}{|c|}{ Non-migrants } & \multicolumn{2}{|c|}{ All } \\
\hline & Mean & Std. Dev. & Mean & Std. Dev. & Mean & Std. Dev. \\
\hline Female headed households & 0.20 & 0.40 & 0.17 & 0.38 & 0.19 & 0.39 \\
\hline Age & 48.25 & 18.39 & 26.59 & 20.11 & 39.28 & 21.89 \\
\hline Child (age $<16)$ & 0.01 & 0.12 & 0.37 & 0.48 & 0.16 & 0.37 \\
\hline Old $($ age $>60)$ & 0.32 & 0.47 & 0.12 & 0.32 & 0.23 & 0.42 \\
\hline Primary education & 0.21 & 0.41 & 0.16 & 0.36 & 0.19 & 0.39 \\
\hline Secondary education & 0.40 & 0.49 & 0.29 & 0.45 & 0.35 & 0.48 \\
\hline Tertiary education & 0.08 & 0.27 & 0.04 & 0.20 & 0.06 & 0.24 \\
\hline Household size & 3.43 & 1.54 & 4.16 & 1.46 & 3.70 & 1.56 \\
\hline Employed & 0.27 & 0.45 & 0.12 & 0.33 & 0.21 & 0.41 \\
\hline Self-employed & 0.06 & 0.23 & 0.03 & 0.16 & 0.04 & 0.21 \\
\hline Unemployed & 0.29 & 0.45 & 0.31 & 0.46 & 0.30 & 0.46 \\
\hline Poor & 0.12 & 0.32 & 0.32 & 0.47 & 0.20 & 0.40 \\
\hline
\end{tabular}

Source: Author's calculations based on LSMS (2001).

Although the results of the descriptive analysis provide a useful insight into the characteristics of the poor in Bosnia, for ultimate conclusions about the relationship between displacement and poverty status of a household, a multiple regression analysis of determinants of urban poverty in Bosnia needs to be conducted. The methodology and results of this analysis are presented in the following sections.

\subsection{The Model}

Analyses of poverty determinants at the micro level are mainly based on two types of regression models: one that regresses a continuous variable for a household's welfare on a set of explanatory variables using the OLS method (Malik, 1996; Fagernäs and Wallace, 2007), and another that uses a binary variable for poverty status of a household as a dependent variable and estimates the model by logit or probit estimation method (Siddiqui, 2009; Ghazouani and Goaied, 2001; Okwi et al., 2007; Geda et al., 2005; Mok, Gan and Sanyal, 2007). Both types of 
models have their own advantages and disadvantages. The main advantage of the first type is that a continuous variable is used, thus providing more detailed information on the effect of the factors analyzed on poverty over the entire welfare distribution. However, some authors consider this as a disadvantage of these models, as they assume that the impact of these variables is constant and same for poor and non-poor households. As both models provide congruent insights, and in order to overcome the limitations of each of the two models, both are estimated in this study. In order to examine the determinants of urban poverty and its link to migration, we estimate both models (OLS and probit) for the entire sample and for the persons living in urban areas. This allows us to check whether urban poverty has specific determinants and if its relation to migration is the same at national and at urban level.

One of the first methodological questions that has to be raised in the analysis of poverty is whether income or expenditures should be used for measuring poverty. The main disadvantage of an income-based poverty measure is the quality of survey data on income, which is generally underreported. On the other hand, use of expenditures is both theoretically and empirically supported. According to Deaton and Muellbauer (1980), use of expenditures has theoretical advantage, because they are deemed to reflect permanent income better. Empirically, income has been found to have several reporting problems in surveys such as the Household Budget Survey. Therefore, the analysis in this study is based on the observed expenditures, i.e., those reported by households. These expenditures include those that directly affect the level of a household's welfare, and exclude health care, imputed rent and investment expenditures.

Another methodological question that arises at this stage is whether absolute or relative poverty lines should be used. The absolute poverty measure used will be a threshold of US\$ $1.25 .{ }^{21}$ In Bosnia, the relative poverty line calculated as 60 percent of median consumption of urban individuals in the dataset is KM

21 Since 2008, this is the World Bank's official poverty measure, and is widely used in countries that prefer absolute poverty lines. 
1,566, while the absolute line is $\mathrm{KM} 656 .{ }^{22}$ Poverty measures based on the absolute poverty line are too low. For example, headcount ratio is 0.5 percent. Consequently, we will use only the relative poverty line for Bosnia in the further analysis.

The dependent variable for the OLS model is logarithm of the total equivalent household consumption ${ }^{23}$, while for the probit model the dependent variable is whether the individual lives in a poor household, i.e., whether its total equivalent household consumption is above or below the poverty line (defined as 60 percent of the total equivalent household income). The set of independent variables used in the analysis is similar to the ones used in the majority of previous studies on the determinants of poverty. As for the individual-level data used, two types of explanatory variables are included in the model: 1) characteristics of the household the individuals live in, and 2) personal characteristics of the individuals. The model is extended by inclusion of a dummy variable capturing displacement status of a household, as a primary objective of the research presented in this paper. In order to measure the impact of migration status on poverty, we include in the model a dummy variable for whether the person is a migrant, and a dummy variable for the direction of her/his migration (migration to the capital).

One of the household characteristics is the education of the household head - dummies are used for a household head with primary education and for a household head with tertiary education. We have chosen these variables because we expect to see a link between the earnings (usually household heads are the main wage earners in the household) and the educational attainment of the household head. As we have already seen in the previous section, living in a household whose head has attained primary education is expected to increase the probability of living in poverty, while the opposite is true for households with highly educated household heads.

22 This poverty line was calculated by multiplying US $\$ 1.25$ by 365 days (as income and consumption data were presented at the annual level) and then by 1.4376, which was the US\$/KM exchange rate on December 31, 2004, according to the Central Bank of Bosnia and Herzegovina (available at http://www.cbbh.ba).

23 The equivalence scale used here is a modified OECD scale, which assigns a value of 1 to the household head, of 0.5 to each additional adult member and of 0.3 to each child (Hagenaars, de Vos and Zaidi, 1994). 
As we may expect the existence of gender inequality of earnings, we also include in the model a dummy variable for whether the household head is female. Two dummies for the residence of living are included in the model as well: living in the capital and living in rural areas. Our expectations are that living in the capital would decrease the probability of living in poverty and living in rural areas would increase it. As the average size of poor households is greater than of non-poor households, we also include a variable for the household size. We expect the regression results to be in line with the descriptive statistics, i.e., we should find a positive relationship between household size and the probability of living in poverty.

As the main income source of the households are incomes from employment, their share in total income is also included in the model. The main hypothesis behind this is that a low number of wage earners in a household (due to unemployment, old or young age) will negatively affect the level of consumption of the household and thus will increase the probability of living in poverty for its members. Because of the importance of remittances for people in $\mathrm{BiH}$, we also include in the model a variable measuring the share of remittances in the total household consumption. The proportion of social payments in the total household income will show us the dependency level on payments provided by the state.

Ownership of the dwelling also influences the consumption model of the household and therefore we include it in the model as well. The rest of the variables are related to the personal characteristics of the individuals such as age, employment status and educational attainment. As mentioned above, being a child in Bosnia increases the probability of living in poverty. Therefore we include two dummies for the age of the individuals (whether they are above 60 years of age and whether they are below 16 years of age). We also include a dummy variable for whether the person is self-employed. 


\section{Results}

The results of the estimations of the OLS and probit models for identifying the determinants of urban poverty in $\mathrm{BiH}$ are presented in Table 4. The results for both models do not differ significantly. ${ }^{24}$ The coefficients of the baseline model have expected signs and size, and are statistically significant at the standard level of significance. We believe that the main variable of interest, the displacement status, does not suffer from errors in measurement, is not determined simultaneously with the living standard by a third cause, and is not affected by the living standard itself (reverse causality). We also believe, although we cannot test the validity of the belief, that the set of control variables is rich enough, so that no important control variable has been omitted. Therefore, the estimate of the effect of displacement status on poverty status is likely free of significant biases. Finally, estimation of different model specifications was performed in order to confirm that the models are not sensitive to inclusion of a particular variable.

The key variables of the model are related to the migration status of a household. As shown in Table 5, we have a dummy variable that indicates whether a person lives in the capital, a dummy variable indicating whether a person migrated during the war, and an interaction term between the two that indicates whether a migrant now lives in the capital. So, the benchmark category is a non-migrant living in an urban area other than the capital city. If we compare coefficients of all the related variables, we can see that households living in the capital (both migrants and non-migrants) have higher average consumption level and are less likely to be poor. This indicates a clear "first city bias" that makes all households living in the capital better off. In contrast, migrant households in other urban areas have lower average consumption level and are more likely to be poor, compared to both non-migrants in their area and migrants in the capital city. The urban setting matters - IDPs who decided to move to the capital city are in a much better situation, i.e., they have higher consumption level and 24 Opposite signs of the coefficients are expected, since the OLS model measures the effect of a particular coefficient on the consumption level, whereas the probit model measures its effect on the probability of being poor. 
are significantly less likely to be poor than the ones who moved to other urban areas. The difference between migrants and non-migrants in the capital city is not statistically significant, meaning that migration status matters only in other urban areas in $\mathrm{BiH}$.

Table 5: Results of the OLS Estimations for Identification of Determinants of Urban Poverty

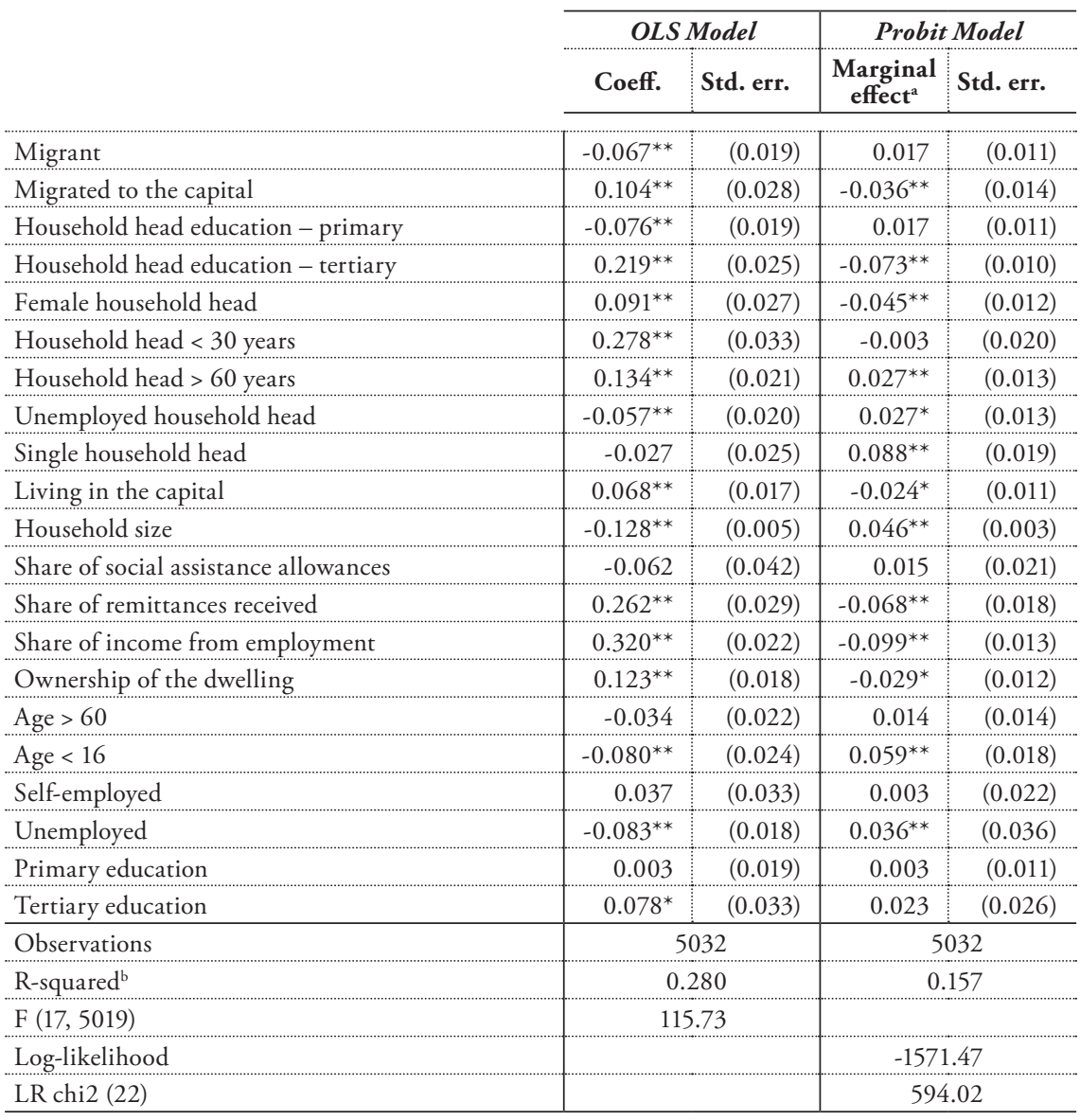

Notes: ${ }^{*}$ denotes statistical significance of a coefficient at $5 \%$ level of significance, ${ }^{* *}$ denotes statistical significance of a coefficient at $1 \%$ level of significance. ${ }^{a}$ Marginal effects are estimated at mean values of continuous variables, and for discrete change from 0 to 1 in case of dummy variables. ${ }^{\mathrm{b}} \mathrm{R}$-squared figure is adjusted $\mathrm{R}^{2}$ for OLS model, and pseudo $\mathrm{R}^{2}$ for probit model.

Source: Author's calculations based on LSMS (2001). 
Besides the influence of key variables explained above, other factors increasing poverty in a household include having an unemployed household head, unemployment status of the individuals and large size of the household. In Bosnia, being a child or living in a household with a single household head also increase the risk of living in poverty. In urban areas in Bosnia, migration to the capital and female household head reduce the risk of living in poverty. Factors decreasing the likelihood for living in poverty in urban areas are: living in the capital, tertiary education of the household head, larger share of income from employment and ownership of the dwelling.

Primary education of the household head is also found to decrease consumption levels; however, it is not significant in the probit model. Another difference between the two models is that young age of the household head, share of food expenditures and tertiary education of the individuals are found in the OLS model to increase household consumption, but they are not found to significantly decrease poverty likelihood.

\section{Conclusions}

In $\mathrm{BiH}$ the urban poverty rate is close to the rural rate overall, and even higher when towns other than the capital city are compared to rural areas. A possible reason could be that during the war in $\mathrm{BiH}$, large numbers of people were displaced and the flows of migration that were mainly directed towards the cities have created a new group vulnerable to poverty in urban areas. These people had to start their lives again with the few assets they had taken from their homes.

The findings produced by statistical and econometric analysis of the national household survey and presented in this paper suggest that migration status of households (if they are urban IDPs or not) matters only in urban areas other than the capital city. Moreover, migrants in the capital city are less likely to be poor than non-migrants in other urban areas. These findings should explain the extent to which migration status and place of living affect the presence of the 
urban poor in different areas in the country, and can be used for a better design and targeting of social assistance and other poverty reduction measures.

Analyzing other determinants of urban poverty, we have found that the main factors affecting poverty are place of living (if in capital city or not), unemployment status of the individuals, their education level and the size of a household. Other determinants increasing the risk for poverty in Bosnia are being under 16 years of age, living in a household with a single household head, larger share of income from employment and ownership of a dwelling. As in other countries as well, the findings suggest that an increase in education and employment, which is equally distributed across the country and not biased strongly towards the capital city, can improve the well-being of the country's inhabitants. Such programs should also take into account the migration status of households.

The process of mass forced displacement explained in this paper stresses the characteristics of the process, which includes forced eviction and implies significant losses of physical and human capital by displaced households. Therefore, for a proper design of poverty reduction policies and programs targeting these people, future research of multidimensional poverty and its determinants among displaced people is suggested.

\section{Literature}

Bell-Fialkoff, Andrew, 1993, "Brief History of Ethnic Cleansing", Foreign Affairs, 72(3), pp. 110-121.

Deaton, Angus and John Muellbauer, 1980, "An Almost Ideal Demand System", American Economic Review, 70(3), pp. 312-326.

Fagernäs, Sonja and Lindsay Wallace, 2007, "Determinants of Poverty in Sierra Leone, 2003”, ESAU Working Paper, No. 19, London: Overseas Development Institute. 
Foster, James, Joel Greer and Erik Thorbecke, 1984, "A Class of Decomposable Poverty Measures", Econometrica, 52(3), pp. 761-766. http://dx.doi. org/10.2307/1913475

Geda, Alemayehu, Niek de Jong, Mwangi S. Kimenyi and Germano Mwabu, 2005, "Determinants of Poverty in Kenya: A Household Level Analysis", Working Paper, No. 2005-44, Department of Economics Working Paper Series, January, Storrs, CT: University of Connecticut.

Ghazouani, Samir and Mohamed Goaied, 2001, "Determinants of Urban and Rural Poverty in Tunisia", paper presented at the workshop "Analysis of Poverty and Its Determinants in the MENA Region", Sanaa, Yemen, July 31 - August 1.

Ibreljic, Izet, Salih Kulenovic, Alma Kadusic and Sabahudin Smajic, 2006, "Migration Flows in Bosnia-Herzegovina and Herzegovina after 1992", paper presented at the "46th ERSA Congress", Volos, Greece, August 30 - September 3.

Kacapor-Dzihic, Zehra and Nermin Oruc, 2012, "Social Impact of Emigration and Rural-Urban Migration in Central and Eastern Europe: Country Report Bosnia and Herzegovina”, Brussels: European Commission.

Kondylis, Florence, 2008, "Conflict Displacement and Labor Market Outcomes in Post-War Bosnia \& Herzegovina”, HiCN Working Paper, No. 45, University of Sussex, Brighton: Households in Conflict Network.

Koser, Khalid and Van Hear, Nicholas, 2003, "Asylum Migration: Implications for Countries of Origin”, WIDER Discussion Paper, No. 2003/20, Helsinki: World Institute for Development Economics Research.

Leckie, Scott, 1994, "Forced Evictions", Environment and Urbanization, 6(1), pp. 131-146. http://dx.doi.org/10.1177/095624789400600111

LSMS, 2001, Basic Information Document - Bosnia and Herzegovina, Washington, D.C.: World Bank. 
Malik, Shahnawaz, 1996, "Determinants of Rural Poverty in Pakistan: A Micro Study", Pakistan Development Review, 35(2), pp. 171-187.

MHRR (Ministry for Human Rights and Refugees), 2005, "Comparative Analysis on Access to Rights of Refugees and Displaced Persons”, Sarajevo: BiH Ministry for Human Rights and Refugees.

Mok, Thai Yoong, Christopher Gan and Amal Sanyal, 2007, "The Determinants of Urban Household Poverty in Malaysia", Journal of Social Sciences, 3(4), pp. 190-196. http://dx.doi.org/10.3844/jssp.2007.190.196

Myers, Norman, 2005, "Environmental Refugees, An Emergent Security Issue", Paper presented to the 13th Economic Forum, Prague, Czech Republic, 23-27 May 2005.

Okwi, Paul O., Godfrey Ndeng'e, Patti Kristjanson, Mike Arunga, An Notenbaert, Abisalom Omolo, Norbert Henninger, Todd Benson, Patrick Kariuki and John Owuor, 2007, "Spatial Determinants of Poverty in Rural Kenya", Proceedings of the National Academy of Sciences of the United States of America, 104(43), pp. 16769-16774. http://dx.doi.org/10.1073/pnas.0611107104

Oruc, Nermin, 2009, "Self-Selection in Conflict-Induced Migration: Micro Evidence from Bosnia", wiiw Balkan Observatory Working Paper, No. 78, Vienna: The Vienna Institute for International Economic Studies.

Oruc, Nermin, 2011, “Do Social Transfers 'Crowd-Out' Remittances: Evidence from Bosnia”, wiiw Balkan Observatory Working Paper, No. 92, Vienna: The Vienna Institute for International Economic Studies.

Siddiqui, Muhamad, 2009, "Determinants of Poverty in Pakistan: Findings from Survey Data 2005”, European Journal of Social Sciences, 12(1), pp. 52-64.

Stark, Oded, 2004, "On the Economics of Refugee Flows," Review of Development Economics, 8(2), pp. 325-329. http://dx.doi.org/10.1111/j.14679361.2004.00236.x 
Turton, David 2003, “Conceptualising Forced Migration”, University of Oxford RSC Working Paper, No. 12, Oxford, UK: University of Oxford.

UNDP, 2007, Social Inclusion in Bosnia and Herzegovina, UNDP National Human Development Report, Sarajevo: UNDP in Bosnia and Herzegovina.

UNHCR, 2014, UNHCR Population Statistics 2013, http://popstats.unhcr.org/ PSQ_POC.aspx (accessed August 29, 2014).

UNICEF, 2008, Legal Aspects of Social Protection for Children in Bosnia and Herzegovina, Unicef Bosnia and Herzegovina.

World Bank, 2006, "Dimensions of Urban Poverty in Europe and Central Asia Region”, Working Paper, No. 36186, World Bank: Infrastructure Department, Europe and Central Asia Region.

Van Hear, Nicholas, 1998, New Diasporas: The Mass Exodus, Dispersal and Regrouping of Migrant Communities, London: University College London Press, and Seattle: University of Washington Press. 